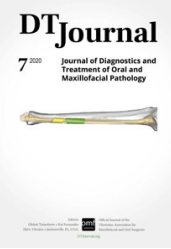

Salivary Glands`Conditions | Ultrasound: Case

\title{
Sialoliths in Ipsilateral Bartholin's and Wharton's Duct: The First Clinical and Ultrasound Report
}

\author{
Dmytro S. Nikulina, levgen I. Fesenkob \& Olha S. Cherniakc,
}

\section{SUMMARY}

Sialoliths in sublingual gland is the rarest condition among sialolithiasis in other major salivary glands. Only in 0.4 percent of cases the salivary stone notes in sublingual gland. In our English literature review we count 8 articles which describe sialoliths located within or around the sublingual glands. Nevertheless, in none of those cases a simultaneous sialolithiasis of the submandibular and sublingual gland was noted. Although in one case the authors described a sonogram of sialolith in the sublingual gland, the sonogram of the gland and its ductal system was not presented. Here we present the first ever published clinical and ultrasound report of combined ductal sialolithiasis of sublingual and submandibular glands in a 78-yearold female. Also, Zhang et al's classification of duct system patterns of the sublingual glands based on 60 cadaveric and 63 clinical cases is analyzed.

Kyiv, Ukraine

a Oral Surgeon, Center of Maxillofacial Surgery, Kyiv Regional Clinical Hospital (place of work at moment of material collection).

${ }^{\mathrm{b}} \mathrm{PhD}$, Assistant Professor, Department of Oral and Maxillofacial Surgery, Private Higher Educational Establishment "Kyiv Medical University"(current position).

Oral Surgeon, Physician of Ultrasound Diagnostics, Center of Maxillofacial Surgery, Kyiv Regional Clinical Hospital (place of work at moment of material collection)

${ }^{c}$ Physician of Ultrasound Diagnostics, Head, Department of Ultrasound, Regional Diagnostic Center, Kyiv Regional Clinical Hospital.

\footnotetext{
* Corresponding author address: 1 Bahhovutivska Street, Kyiv 04107, Ukraine.

Department of Ultrasound, Regional Diagnostic Center, Kyiv Regional Clinical Hospital.

E-mail:cherniak.os@gmail.com (Olha Cherniak)
}

Please cite article as: Nikulin DS, Fesenko II, Cherniak OS. Sialoliths in ipsilateral Bartholin's and Wharton's duct: the first clinical and ultrasound report. J Diagn Treat Oral Maxillofac Pathol 2020;4(7):112-8.

Paper received 3 May 2020

Accepted 9 June 2020

Available online 31 July 2020

httpi://dx.doi.org/10.23999/j.dtomp.2020.7.2.

(C) 2020 OMF Publishing, LLC. This is an open access article under the CC BY license (http://creativecommons.org/licenses/by-nc/4.0/). 


\section{INTRODUCTION}

Sialoliths in sublingual gland is the rarest condition among sialolithiasis in other major salivary glands. ${ }^{1,2}$ Only in 0.4 percent of cases the salivary stone (synonyms: sialolith, salivary calculus, and concrement) notes in sublingual gland. ${ }^{1}$

Ultrasound (US) appearance of sialoliths in submandibular/parotid gland and its ducts is perfectly described in many publications..$^{3-5}$ Ultrasonographic and clinical pattern of mucus plugs are also recently highlighted. ${ }^{6}$ But, in English literature is absent the data which reported ultrasound images (synonym: sonograms) of sialoliths located in both the main duct of the sublingual gland (ie, Bartholin's duct) and in ipsilateral duct of the submandibular gland (ie, Wharton`s duct). In our English literature review we count 8 articles which describe sialoliths located within or around the sublingual glands. ${ }^{1,7-13}$ But in English literature the data are absent which reported a simultaneous sialolithiasis of the submandibular and sublingual gland. Despite in one case the authors described US of sialolith in the sublingual gland, the sonogram of the gland was not presented. ${ }^{13}$ Until recently, no ultrasonographic appearance of sublingual gland`s ductal system was shown.

We presented the first ever published clinical and US report of combined sialolithiasis of sublingual and submandibular glands in a 78-year-old female. Also,
Zhang et al's classification of duct system patterns of the sublingual glands based on 60 cadaveric and 63 clinical cases is analyzed. ${ }^{14}$

\section{CASE}

In May 2015, a 78-year-old female presented to the maxillofacial surgery center with chief complaints of the salivary colics and moderate firm swelling in the right submandibular region. Bimanual palpation revealed painful and swelled right submandibular gland. Intraoral examination showed diffuse swelling of the right sublingual area with moderate mucosal erythema. No fluid milked from the right sublingual caruncle.

US examination (synonym: ultrasonography) was performed with $12-3 \mathrm{MHz}$ linear probe (synonym: linear transducer) (model HD11 XE, Philips). Gray scale US revealed enlarged ill-defined right submandibular and sublingual gland. Structure of which were less echogenic than the contralateral glands. Dilated intraglandular duct and sonographic architecture of the right submandibular gland is shown in Figure 1.

According to the sonograms the Bartholin's duct (Fig 2) of the right sublingual gland joined the Wharton's duct and opened together at the sublingual caruncle. US picture in that case represented type 2 of Zhang et al's classification of the duct system patterns in the sublingual glands. ${ }^{14}$
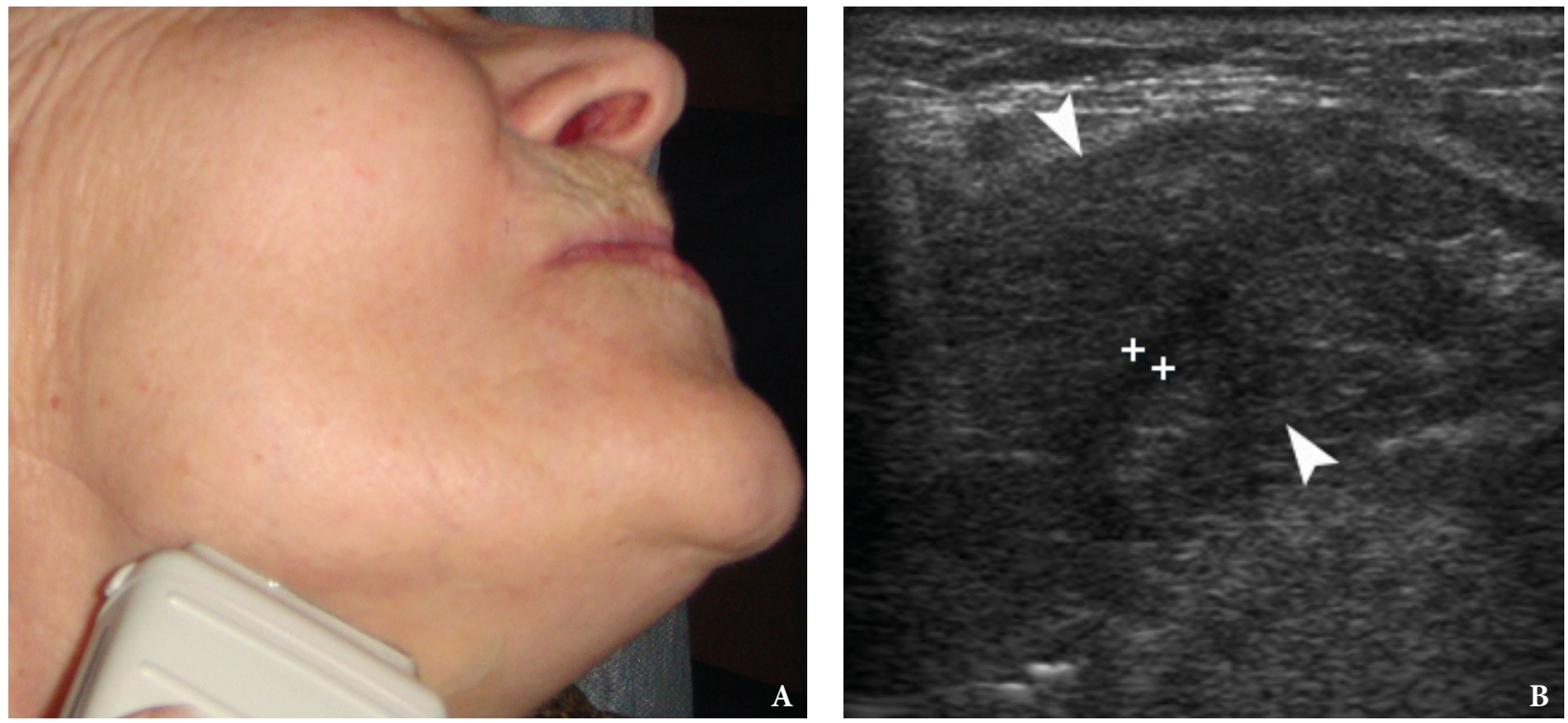

FIGURE 1. Image A shows position of linear probe. On gray scale sonogram (B) notes dilated intraglandular duct (is indicated by 't' calipers) measured 1.6 $\mathrm{mm}$ in the right submandibular gland (arrowheads). 
Intraglandular duct system of the right sublingual gland was dilated. Also, in the significantly dilated lumen of the Bartholin's duct a hyperechoic curvilinear body measured $\sim 2.8 \mathrm{~mm}$ was visualized. Another bright curvilinear echo measured $\sim 0.9$ $\mathrm{cm}$ was located in the area of fusion between the Bartholin's and Wharton's duct. Both bodies created the artifacts of complete posterior shadowing (synonym: acoustic shadowing).

US appearance of both ipsilateral glands with its ducts corresponds to the diagnosis of exacerbation of chronic calculous sialadenitis ${ }^{2}$ of sublingual and submandibular glands (synonym: obstructive sialadenitis of sublingual and submandibular glands due to sialoliths). And the sialithsectomy was chosen as a surgical tactic due to the intraductal localization of the calculi in Bartholin's and Wharton`s duct.

Removal of the salivary stones (synonyms: sialolithotomy, ${ }^{15}$ sialolithectomy ${ }^{13,16}$ ) was done under local anesthesia. Sialolith which located in the Wharton's duct was removed in two parts during a first stage and is visualized at Figure 3 as yellowish stone measured $0.55 \mathrm{~cm}$. Smaller one, a $0.3-\mathrm{cm}$ stone, was removed in a second stage. Removal of the stones accompanies with receiving of insignificant volume of the suppurated saliva. Post-
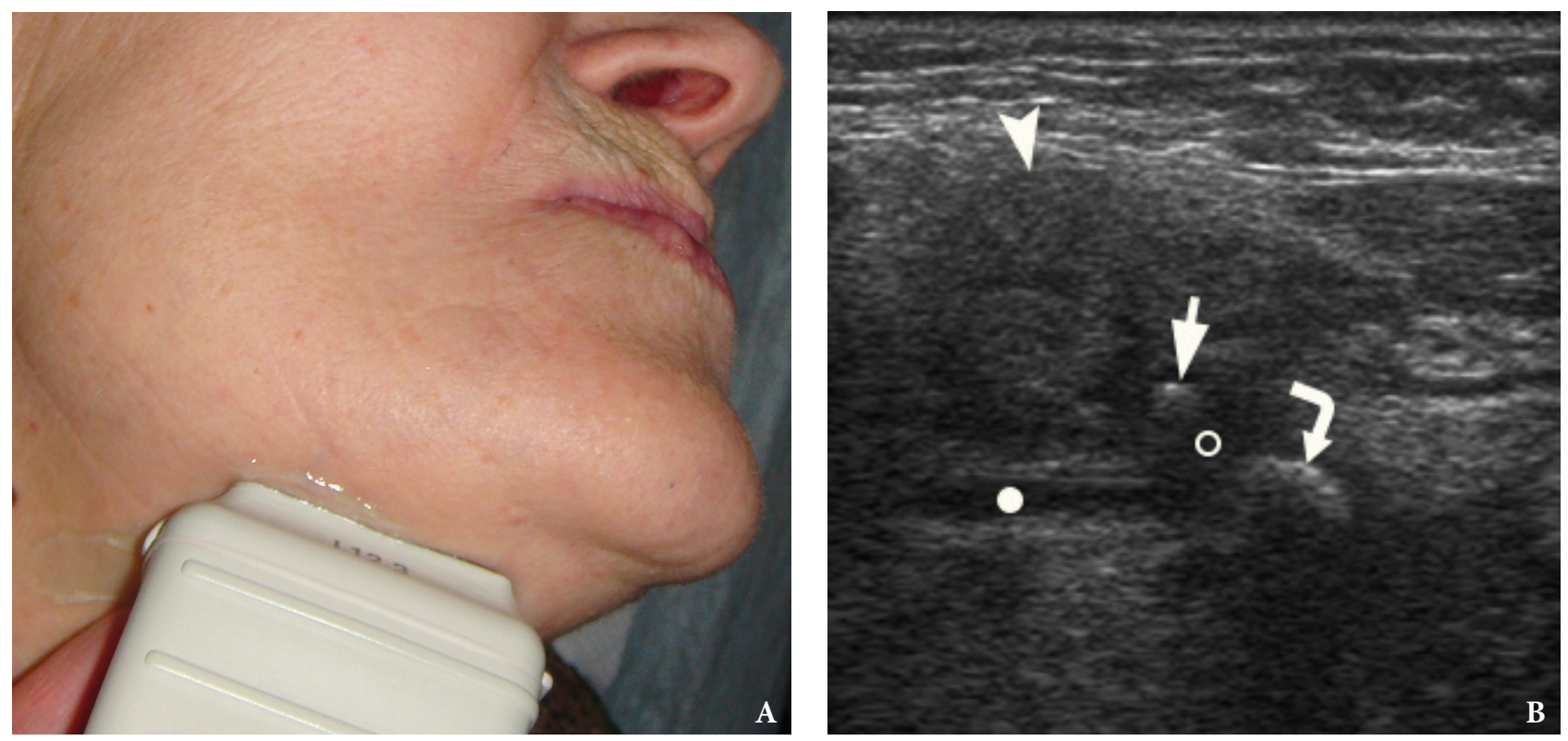

operative recommendations included massage of the right submandibular gland and non-steroidal antiinflammatory drugs.

Regression of the clinical and ultrasound symptoms of obstruction in both glands was noted on the next day after the removal of calculi. At 1-month follow-up ultrasonography the right submandibular (Fig 4) and sublingual gland are visualized as ill-defined organs and has hypoechoic heterogenic structures comparing with contralateral glands. That fact indicates on irreversible inflammatory changes of the glands' parenchyma. Nevertheless, intraglandular ducts dilatation was absent.

\section{DISCUSSION}

This is a case of highly effective using of ultrasonography in the practice of oral and maxillofacial surgeons for diagnostics and treatment of extremely rare sialolithiasis in both Bartholin`s and Wharton's duct.

Correct analysis of sonograms was based not only on understanding of basic US principles but also on perfect knowledge of examined body area, possible pathologic conditions, and clinical thinking.

So, the shape of the sublingual gland resembles

FIGURE 2. A 78-year-old woman with symptoms of acute obstructive submandibular sialadenitis. Linear probe placed in a position (A) for US examination of the right sublingual gland (arrowhead). Gray scale sonogram (B) shows dilated Wharton `s duct (white dot), small sialolith (arrow) within the significantly dilated Bartholin 's duct (circle), and bigger stone (curved arrow) in a place where the major duct of sublingual gland joins the duct of the submandibular gland. Acoustic shadowing noted behind each calculus. 


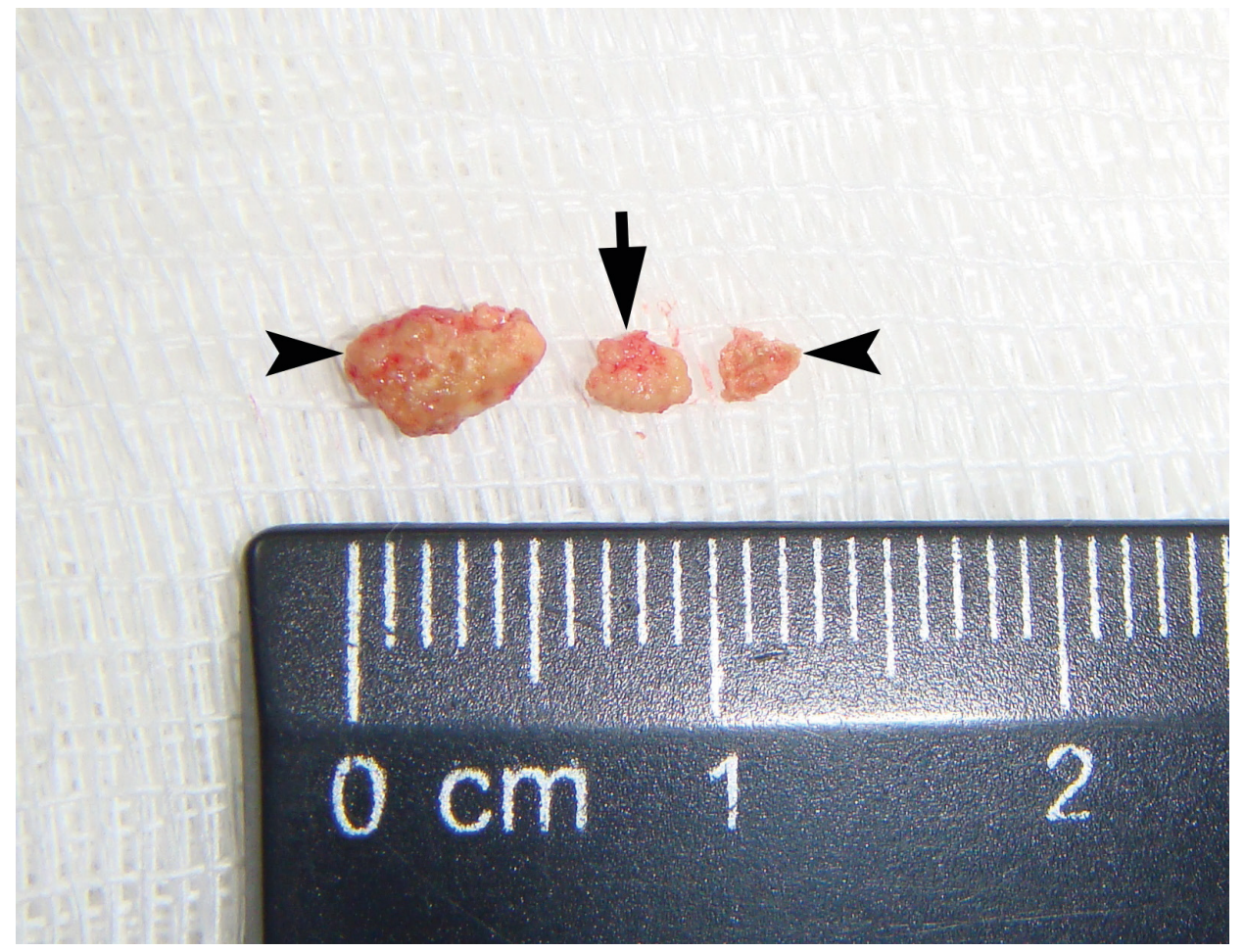

FIGURE 3. Salivary stones after removal. Two parts of one 0.55 -cm sialolith located in the Wharton `s duct are labeled by arrowheads and $\sim 0.3-\mathrm{cm}$ calculus located in the main Bartholin 's duct is indicated by arrow.
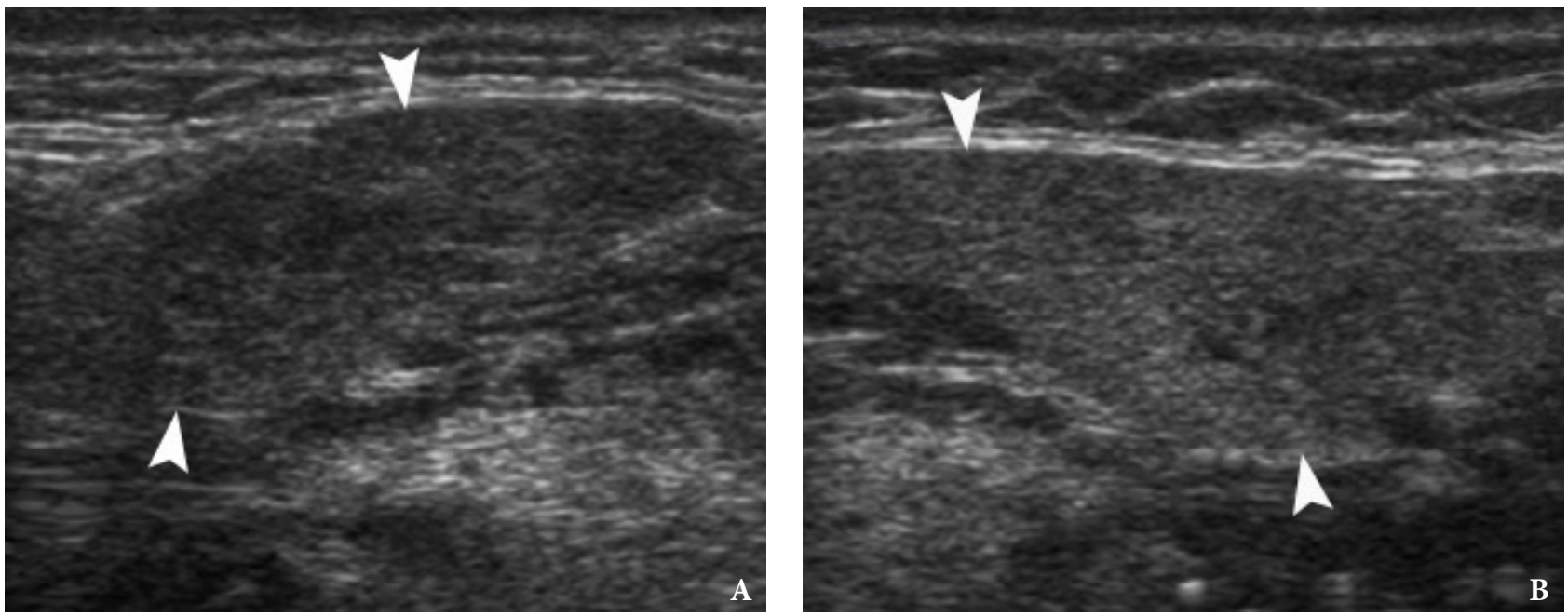

FIGURE 4. 1-month follow-up ultrasonography. Gray scale sonograms show comparison of right (A) and left (B) submandibular glands (arrowheads). Right submandibular gland is ill-defined and has a hypoechoic heterogenic structure comparing with contralateral gland. That indicates on irreversible inflammatory changes of the gland 's parenchyma. Intraglandular duct dilatation is absent. 
the large tadpole $^{17}$ or almond ${ }^{18}$. The typical anatomical features of the sublingual gland are next: consists of two parts (head and tail), lack of capsule/ fascial sheath, surrounded by loose connective tissue, ${ }^{18}$ the tail in some cases is in contact with submandibular gland. ${ }^{17}$ In contrast to the parotid and submandibular glands, the anatomy and number of ducts of the sublingual salivary gland can be in one of three anatomical types what is represented in Table $1 .{ }^{14}$ The minor ducts is also termed as "fine ducts," 14 "ducts of Rivinus"17 or "Rivini"s ducts"18. The Bartholin's duct not is attached to the floor of mouth mucosa ${ }^{17}$, but Rivini's ducts (a group of ducts) firmly attached to the mucous membrane and penetrated it. Number of minor ducts varies in the literature, indicated not only from 8 to 15 ducts openings, ${ }^{14}$ but also $15-30$ salivary ductules. ${ }^{17}$ This is why it is so difficult to dissect the sublingual gland from mucosa at the anterior (head) part of the gland. Variations of Bartholin's duct origin according to the different studies is highlighted in Table 2.

So, in cases when the duct systems of the submandibular and sublingual glands are united (ie, type 2 of anatomic variation) $)^{14}$ for the better understanding of possible pathologic condition, like sialolithiasis or obstructive sialadenitis, it is possible to apply the term "two salivary glands, one duct system." This thesis is proved and highlighted by our case ductal system which belongs to type 2 . In the similar pattern 2 ductal systems the calculus which is located in the Wharton's duct in area of junction with Bartholin's duct can theoretically provoke obstructive sialadenitis of the sublingual gland or even formation of own calculi in the sublingual gland and vice versa.

Ying et al noticed in post-sialadenectomy cases the communication between Bartholin's and Wharton's duct and the fact that "viscous saliva in the relatively stagnant environment within the residual part of the Wharton's duct further facilitates sialolith formation." ${ }^{19}$

We agree with Güvenç et al, due to complicated anatomy of the ducts in sublingual-submandibular gland system, the origin of the calculi in sublingual region is difficult to find. ${ }^{13}$ It can be an explanation why among 8 previously reported cases of sialolithiasis in the area of sublingual gland (Table 3) the indicated locations of salivary stones was not always the sublingual gland itself ${ }^{8,9,11}$, but also a sublingual region ${ }^{7,10,12,13}$.

In the majority of reported cases with sublingual gland sialolithiasis the gland was removed. In our case, precise US diagnostics of intraductal localization of sialoliths and successfully performed sialolithsectomy allows to manage the obstructive sialadenitis and to avoid sublingual and submandibular glands removal.

TABLE 1. Zhang et al 's Classification of Duct System Patterns of the Sublingual Glands Based on 60 Cadaveric and 63 Clinical Cases. ${ }^{14}$

\begin{tabular}{|c|l|c|c|}
\hline Duct System Pattern & \multicolumn{1}{|c|}{ Description } & Mean Diameter & $\begin{array}{c}\text { Percent in Cadaveric and } \\
\text { Clinical Cases }\end{array}$ \\
\hline Type 1 & $\begin{array}{l}\text { Only minor ducts of the sublingual gland communicating } \\
\text { with the oral mucous membrane. }\end{array}$ & $0.98 \pm 0.10 \mathrm{~mm}$ & 36.7 and $36.8 \%$ \\
\hline Type 2 & $\begin{array}{l}\text { The major duct of sublingual gland fused with the middle } \\
\text { part of Wharton`s duct. }\end{array}$ & $2.13 \pm 0.52 \mathrm{~mm}$ & 40 and $52.9 \%$ \\
\hline Type 3 & $\begin{array}{l}\text { Bartholin`s duct coursed separately from the Wharton`s } \\
\text { duct and opened at the sublingual caruncle. }\end{array}$ & $3.25 \pm 1.26 \mathrm{~mm}$ & 23.3 and $10.3 \%$ \\
\hline
\end{tabular}

TABLE 2. Variations of Bartholin `s Duct Origin According to the Different Studies.

\begin{tabular}{|l|l|}
\hline \multicolumn{1}{|c|}{ Bartholin`s Duct Origin } & \multicolumn{1}{|c|}{ Title and Year of Publication } \\
\hline The Bartholin`s duct originates from the center of the gland. & $\begin{array}{l}\text { Clinical and anatomic study on the ducts of the submandibular } \\
\text { and sublingual glands (2010). }{ }^{14}\end{array}$ \\
\hline $\begin{array}{l}\text { Sublingual gland is drained from the anterior part of the gland } \\
\text { through the Bartholin's duct. }\end{array}$ & Histopathology of the salivary glands (2014). ${ }^{18}$ \\
\hline $\begin{array}{l}\text { The tail, when present (>65\%), is a single discrete secretory unit, } \\
\text { which drains only by a Bartholin`s duct. }\end{array}$ & Sublingual gland (2018). ${ }^{17}$ \\
\hline
\end{tabular}


TABLE 3. Articles Describing Calculi within and around the Sublingual Gland.

\begin{tabular}{|c|c|c|c|c|c|c|}
\hline$\#$ & $\begin{array}{c}\text { Patient: } \\
\text { Age (Yrs) and } \\
\text { Gender }\end{array}$ & $\begin{array}{l}\text { Presented } \\
\text { Imaging }\end{array}$ & $\begin{array}{l}\text { No. of Sialoliths } \\
\text { and Its Location }\end{array}$ & $\begin{array}{c}\text { Simultaneous Sialolithiasis/ } \\
\text { Obstructive Sialadenitis } \\
\text { of the Ipsilateral } \\
\text { Submandibular Gland }\end{array}$ & $\begin{array}{l}\text { Removal of } \\
\text { the gland }\end{array}$ & $\begin{array}{c}\text { Article's Title and Year of } \\
\text { Publication }\end{array}$ \\
\hline 1 & Not indicated & Not indicated & 1 & Not mentioned & $\begin{array}{c}\text { Not } \\
\text { mentioned }\end{array}$ & $\begin{array}{l}\text { Sialolithiasis. A survey on } \\
245 \text { patients and a review } \\
\text { of the literature (1990). }{ }^{1}\end{array}$ \\
\hline 2 & $28 / \mathrm{F}$ & X-Ray + CT & $\begin{array}{l}22 \text { : inside and } \\
\text { around the } \\
\text { sublingual gland }\end{array}$ & No & Yes & $\begin{array}{l}\text { Multiple sialoliths in } \\
\text { sublingual gland: report of } \\
\text { a case (2002). }\end{array}$ \\
\hline 3 & $12 / \mathrm{F}$ & CT & $\begin{array}{l}\text { 5: within the } \\
\text { sublingual gland }\end{array}$ & No & Yes & $\begin{array}{l}\text { Sialolithiasis in the } \\
\text { sublingual gland (2003). }{ }^{8}\end{array}$ \\
\hline 4 & $50 / \mathrm{M}$ & $\mathrm{CT}$ & $\begin{array}{l}\text { 1: within the } \\
\text { sublingual gland }\end{array}$ & No & Yes & $\begin{array}{l}\text { Sublingual gland } \\
\text { sialolithiasis: a case report } \\
(2007) \cdot{ }^{9}\end{array}$ \\
\hline 5 & $59 / \mathrm{M}$ & $\mathrm{X}$-Ray + CT & $\begin{array}{l}1: \text { in area of the } \\
\text { sublingual gland }\end{array}$ & No & Yes & $\begin{array}{l}\text { Giant sublingual sialolith } \\
\text { leading to dysphagia } \\
(2010) .{ }^{10}\end{array}$ \\
\hline 6 & $35 / \mathrm{F}$ & X-Ray & $\begin{array}{l}5: \text { in the } \\
\text { sublingual gland }\end{array}$ & No & Yes & $\begin{array}{l}\text { Incidental finding of } \\
\text { sialolithiasis in the } \\
\text { sublingual gland: a } \\
\text { diagnostic dilemma } \\
(2011) .{ }^{11}\end{array}$ \\
\hline 7 & $67 / \mathrm{F}$ & CT & $\begin{array}{l}\text { 268: anterior to } \\
\text { the sublingual } \\
\text { gland }\end{array}$ & No & No & $\begin{array}{l}\text { Multiple sialolithiasis in } \\
\text { sublingual gland causing } \\
\text { dysphagia (2012). } .^{12}\end{array}$ \\
\hline 8 & $67 / \mathrm{M}$ & $\begin{array}{l}\text { CT + MR; US is } \\
\text { described (1.5- } \times \\
1-\mathrm{cm} \text { stone in the } \\
\text { right sublingual } \\
\text { area) but not } \\
\text { presented }\end{array}$ & $\begin{array}{l}\text { 1: in sublingual } \\
\text { area }\end{array}$ & $\begin{array}{l}\text { No; Submandibular gland } \\
\text { was absent due to agenesis. }\end{array}$ & No & $\begin{array}{l}\text { Unilateral submandibular } \\
\text { gland agenesis associated } \\
\text { with sublingual } \\
\text { sialolithiasis perforating the } \\
\text { floor of the mouth (2017). }{ }^{13}\end{array}$ \\
\hline 9 & $78 / \mathrm{F}$ & US & $\begin{array}{l}\text { 2: } 1 \text { in Bartholin`s } \\
\text { duct and } 1 \text { in } \\
\text { Wharton's duct }\end{array}$ & Yes & No & $\begin{array}{l}\text { Our case: Sialoliths in } \\
\text { ipsilateral Bartholin`s and } \\
\text { Wharton`s duct: The first } \\
\text { clinical and ultrasound } \\
\text { report (2020). }\end{array}$ \\
\hline
\end{tabular}

\section{CONCLUSIONS}

We hope this rare report may serve as a guiding star for further ultrasound investigation of pathologic conditions in sublingual glands and its ductal system. Simultaneously, it can be a new chapter in implementation of ultrasonography into daily practice of oral and maxillofacial surgeons.

\section{ROLE OF CO-AUTHORS}

Dmytro S. Nikulin (editing).

Ievgen I. Fesenko (material collection, concept of the article, writing, and editing).

Olha S. Cherniak (material collection).

All authors read and approved the final manuscript. 


\section{TERM OF CONSENT}

No needed.

\section{FUNDINGS}

No funding was received for this study.

\section{ACKNOWLEDGMENTS}

The authors are grateful to Dr. Oleksii O. Tymofieiev for the reference advices.

\section{REFERENCES}

1. Lustmann J, Regev E, Melamed Y. Sialolithiasis. A survey on 245 patients and a review of the literature. Int J Oral Maxillofac Surg 1990;19(3):135-8.

2. Tymofieiev OO. Manual of maxillofacial and oral surgery [Russian]. 5th ed. Kyiv: Chervona Ruta-Turs; 2012.

3. Huang F, Caton R, Colla J. Point-of-care ultrasound diagnosis of acute sialolithiasis with sialadenitis. Clin Pract Cases Emerg Med 2017;1(4):437-8.

4. Tymofieiev OO, Cherniak OS. Ultrasound in the detection of floating sialoliths. J Diagn Treat Oral Maxillofac Pathol 2019;3(8):196-7.

5. Konstantinidis I, Paschaloudi S, Triaridis S, Fyrmpas G, Sechlidis S, Constantinidis J. Bilateral multiple sialolithiasis of the parotid gland in a patient with Sjögren's syndrome. Acta Otorhinolaryngol Ital 2007;27(1):41-4.

6. Cherniak OS, Fesenko II. Effectiveness of ultrasound in verification of the mucus plugs and sialoliths of the Wharton`s duct. J Diagn Treat Oral Maxillofac Pathol 2019;3(5):144-53.

7. Choi J, Kim IK, Oh NS. Multiple sialoliths in sublingual gland: report of a case. Int J Oral Maxillofac Surg 2002;31(5):562-3.
8. Hong KH, Yang YS. Sialolithiasis in the sublingual gland. J Laryngol Otol 2003;117(11):905-7.

9. Liao LJ, Hsiao JK, Hsu WC, Wang CP. Sublingual gland sialolithiasis: a case report. Kaohsiung J Med Sci 2007;23(11):590-3.

10. Güngörmüş M, Yavuz MS, Yolcu U. Giant sublingual sialolith leading to dysphagia. $J$ Emerg Med 2010;39(3):e129-e130.

11. Pace C, Ward S. Incidental finding of sialolithiasis in the sublingual gland: a diagnostic dilemma. Dent Update 2011;38(10):704-5.

12. Eyigor H, Osma U, Yllmaz MD, Selcuk OT. Multiple sialolithiasis in sublingual gland causing dysphagia. Am J Case Rep 2012;13:44-6.

13. Güvenç IA, Eşki E, Yerli H. Unilateral submandibular gland agenesis associated with sublingual sialolithiasis perforating the floor of the mouth. Clin Surg 2017;2:1638.

14. Zhang L, Xu H, Cai ZG, Mao C, Wang Y, Peng X, Zhu $\mathrm{ZH}$, Yu GY. Clinical and anatomic study on the ducts of the submandibular and sublingual glands. J Oral Maxillofac Surg 2010;68(3):606-10.

15. Cho SH, Han JD, Kim JH, Lee SH, Jo JB, Kim CH, Kim BJ. Removal of submandibular calculi by surgical method and hydraulic power with curved needle: a case report. J Korean Assoc Oral Maxillofac Surg 2017;43(3):182-5.

16. Zenk J, Constantinidis J, Al-Kadah B, Iro H. Transoral removal of submandibular stones. Arch Otolaryngol Head Neck Surg 2001;127(4):432-6.

17. Bradley PJ. Sublingual gland. Oper Tech Otolayngol Head Neck Surg 2018;29(3):168-76.

18. Hellquist H, Skalova A. Histology. In: Histopathology of the salivary glands. Berlin Heidelberg: SpringerVerlag; 2014.

19. Ying X, Kang J, Zhang F, Dong H. Recurrent sialoliths after excision of the bilateral submandibular glands for sialolithiasis treatment: a case report. Exp Ther Med 2016;11(1):335-7. 